\title{
Multidomain interventions: state-of-the-art and future directions for protocols to implement precision dementia risk reduction. A user manual for Brain Health Services-part 4 of 6
}

Alina Solomon ${ }^{1,2,3^{*}+}$, Ruth Stephen ${ }^{1 \dagger}$, Daniele Altomare ${ }^{4,5}$ D, Emmanuel Carrera ${ }^{6}$, Giovanni B. Frisoni ${ }^{4,5}$, Jenni Kulmala ${ }^{2,7,8}$, José Luis Molinuevo ${ }^{9}$, Peter Nilsson ${ }^{10}$, Tiia Ngandu ${ }^{2,7}$, Federica Ribaldi ${ }^{4,511,12}$, Bruno Vellas ${ }^{13}$, Philip Scheltens ${ }^{14}$, Miia Kivipelto ${ }^{1,2,3,7,15}$ and on behalf of the European Task Force for Brain Health Services

\begin{abstract}
Although prevention of dementia and late-life cognitive decline is a major public health priority, there are currently no generally established prevention strategies or operational models for implementing such strategies into practice. This article is a narrative review of available evidence from multidomain dementia prevention trials targeting several risk factors and disease mechanisms simultaneously, in individuals without dementia at baseline. Based on the findings, we formulate recommendations for implementing precision risk reduction strategies into new services called Brain Health Services. A literature search was conducted using medical databases (MEDLINE via PubMed and SCOPUS) to select relevant studies: non-pharmacological multidomain interventions (i.e., combining two or more intervention domains), target population including individuals without dementia, and primary outcomes including cognitive/functional performance changes and/or incident cognitive impairment or dementia. Further literature searches covered the following topics: sub-group analyses assessing potential modifiers for the intervention effect on cognition in the multidomain prevention trials, dementia risk scores used as surrogate outcomes in multidomain prevention trials, dementia risk scores in relation to brain pathology markers, and cardiovascular risk scores in relation to dementia. Multidomain intervention studies conducted so far appear to have mixed results and substantial variability in target populations, format and intensity of interventions, choice of control conditions, and outcome measures. Most trials were conducted in high-income countries. The differences in design between the larger, longer-term trials that met vs. did not meet their primary outcomes suggest that multidomain intervention effectiveness may be dependent on a precision prevention approach, i.e., successfully identifying the at-risk groups who are most likely to benefit. One such successful trial has already developed an operational model for
\end{abstract}

\footnotetext{
* Correspondence: alina.solomon@uef.fi

${ }^{\dagger}$ Alina Solomon and Ruth Stephen contributed equally to this work (shared first author)

${ }^{1}$ Institute of Clinical Medicine, University of Eastern Finland, Kuopio, Finland ${ }^{2}$ Division of Clinical Geriatrics, NVS, Karolinska Institutet, Stockholm, Sweden Full list of author information is available at the end of the article
} 4.0 International License, which permits use, sharing, adaptation, distribution and reproduction in any medium or format, as long as you give appropriate credit to the original author(s) and the source, provide a link to the Creative Commons licence, and indicate if changes were made. The images or other third party material in this article are included in the article's Creative Commons licence, unless indicated otherwise in a credit line to the material. If material is not included in the article's Creative Commons licence and your intended use is not permitted by statutory regulation or exceeds the permitted use, you will need to obtain permission directly from the copyright holder. To view a copy of this licence, visit http://creativecommons.org/ licenses/by/4.0/. The Creative Commons Public Domain Dedication waiver (http://creativecommons.org/publicdomain/zero/1. 0/) applies to the data made available in this article, unless otherwise stated in a credit line to the data. 


\begin{abstract}
implementing the intervention into practice. Evidence on the efficacy of risk reduction interventions is promising, but not yet conclusive. More long-term multidomain randomized controlled trials are needed to fill the current evidence gaps, especially concerning low- and middle-income countries and integration of dementia prevention with existing cerebrovascular prevention programs. A precision risk reduction approach may be most effective for dementia prevention. Such an approach could be implemented in Brain Health Services.
\end{abstract}

Keywords: Brain Health Services, Dementia, Aging, Alzheimer's disease, Prevention, Dementia risk, Risk reduction

\section{Background}

Although prevention of dementia and late-life cognitive decline is a major public health priority, there are currently no generally established prevention strategies or operational models for implementing such strategies into practice [1]. During the past 20 years, epidemiological studies have pointed out several modifiable risk factors for dementia, including cardiovascular, metabolic, and lifestyle-related factors (e.g., hypertension, hyperlipidemia, diabetes, obesity, physical inactivity, unhealthy dietary habits, smoking, excessive alcohol consumption, social isolation) [2]. In 2019, the World Health Organization (WHO) published the first guidelines for risk reduction of cognitive decline and dementia [3]. The guidelines were developed to provide evidence-based recommendations on interventions aiming to delay or prevent the onset of cognitive decline and dementia. The reviewed evidence covered interventions including physical activity, tobacco cessation, nutrition, cognitive training, social activity, interventions for alcohol use disorders, and management of weight, hypertension, diabetes, dyslipidemia, depression, and hearing loss [3].

According to the $\mathrm{WHO}$, these risk reduction guidelines are targeted primarily at healthcare providers working at a first- or second-level facility or at the district level, including basic outpatient and inpatient services. While the WHO has pointed out several key considerations for implementation, it is not yet fully clear exactly how the recommendations should be tailored to specific populations, as well as different healthcare system contexts. Due to the complex multifactorial etiology of dementia, and variations in risk factors between different individuals and populations, a "one-size-fits-all" approach to prevention is not going to work. The current risk reduction guidelines are also based on interventions targeting single risk factors. However, overall dementia risk is most often the result of a combination of risk and protective factors that may have different contributions in different individuals or at different life stages. Thus, a precision risk reduction approach is most likely to be effective, i.e., tailoring the right interventions for the right people and at the right time. Operational models for the risk reduction interventions would also have to take into account the local or national specifics of both public health policies and healthcare systems.
Early identification of at-risk individuals is an essential part of the precision risk reduction approach. Many multifactorial dementia risk scores have already been developed for the early identification of at-risk individuals who may also benefit most from preventive interventions [4]. Although such risk scores could in principle facilitate precision risk reduction by, e.g., highlighting an individual's specific combination of risk factors and facilitating more tailored interventions, the majority of such risk scores are not yet sufficiently validated and/or have not been tested in actual prevention trials. In addition, dementia shares many risk factors with other chronic diseases such as cardiovascular conditions (CVD), diabetes, or stroke. Validated risk scores for such conditions are already used as part of the established prevention programs [5]. However, it is not clear to what extent vascular/diabetes risk scores could be useful in the context of dementia prevention and facilitate the integration of dementia prevention within other established prevention programs.

This article is a narrative review of available evidence from multidomain dementia prevention trials targeting several risk factors and disease mechanisms simultaneously, in individuals without dementia at baseline. A key aspect of the evidence review concerns the use of dementia and CVD risk scores in such prevention trials. Based on the findings, we formulate some practical recommendations for implementing precision risk reduction strategies (see Table 1) into new services called Brain Health Services (BHSs). Currently, dementia prevention falls under the domain of memory clinics. However, the current memory clinics have been designed for the needs of patients with overt cognitive and/or behavioral disorders and are ill-equipped to deal with a population of cognitive unimpaired individuals and their growing demand for dementia prevention and cognitive enhancement interventions [6]. We envision the development of new BHSs, with specific missions including dementia risk profiling [7], dementia risk communication [8], dementia risk reduction (the present paper), and cognitive enhancement [9] and with specific societal challenges [10]. This will be the fourth part of a Special Issue series of six articles, published in Alzheimer's Research $\mathcal{E}$ Therapy, which together provide a user manual for BHSs. 
Table 1 Recommendations for practical implementation of precision dementia risk reduction interventions

\section{Target populations \\ - A risk reduction intervention should not be applied unselectively (focus on various at-risk groups). \\ - At-risk groups should be preferably selected using validated risk scores or algorithms. \\ - The most suitable risk score or algorithm should be carefully chosen to fit the purpose, e.g., stage of the risk/disease continuum, age group, level of cognitive performance, and type of intervention to be applied. For example, for multidomain lifestyle interventions, the risk score/ algorithm should select individuals with the type of risk profile that the intervention aims to modify. \\ - Risk reduction interventions should preferably start early, before substantial brain pathology and cognitive/functional impairment have already occurred. \\ - People with genetic susceptibility for dementia (e.g., based on APOE $\varepsilon 4$ genotype) may also benefit from early risk reduction interventions. This should be further investigated in intervention studies. \\ 2. Interventions \\ - Multidomain interventions (targeting several risk factors and disease mechanisms simultaneously) may be needed for an optimal dementia risk reduction. \\ - Interventions should (i) do the right things and (ii) do enough for them, i.e., target an individual's overall risk profile with sufficient intensity to produce an effect. Only general healthy lifestyle advice may not be enough, and a more structured intervention program should be proposed. \\ - Intervention content should be adapted to local/national risk context (e.g., some risk factors may be more prevalent/severe in some countries than others) and various settings and integrated with other chronic non-communicable diseases risk reduction programs when feasible. - Radical lifestyle changes may be difficult to both initiate and maintain longer term. Smaller changes gradually introduced across multiple lifestyle domains may facilitate long-term adherence. \\ - As the social component is important, group sessions and/or group activities should be facilitated when feasible. \\ - New technology may facilitate effective, personalized, and feasible interventions and implementation (eHealth and mHealth). \\ - Intervention effects should be monitored. Risk scores could be useful for this purpose as well, if they include modifiable factors and are sufficiently sensitive to change over time.}

\section{Multidomain interventions}

\section{Effects of multidomain interventions on cognition and related outcomes}

An English-language literature search was conducted using medical databases (MEDLINE via PubMed and SCOPUS, until December 2020) and keywords such as "multidomain," "intervention," "dementia," "cognition," "cognitive decline," and "risk reduction." The following criteria were used to select relevant studies: nonpharmacological multidomain interventions (defined as combining two or more intervention domains), target population including individuals without dementia at baseline, and primary outcomes including cognitive/ functional performance and/or incident mild cognitive impairment (MCI) or dementia. The 14 identified studies are summarized in Table 2.

Most of the trials were conducted in high-income countries. There was a substantial variability in the target populations, format and intensity of the interventions, choice of control conditions, and outcome measures. Recruited participants were aged between 40 and 80 years and varied from relatively unselected primary care populations to general populations with risk factors for dementia, and patients with MCI. The sample size ranged from 56 to 3526 participants and duration of the intervention from 8 weeks to 10 years (1 year or longer in 9 out of 14 trials). The interventions included intensive lifestyle programs offering various combinations of diet advice, dietary supplements, physical exercise advice and/or training programs, cognitive training, and management of vascular/metabolic risk factors. The intervention groups were compared to standard care, placebo, general information/health advice, or sham exercises.

Overall, the results appear to be mixed. Smaller $(N<$ 160 participants) and/or shorter trials (up to 24 weeks) seemed more likely to report intervention benefits on overall cognition and some specific domains (e.g., spatial working memory, executive functioning). Of the 5 larger ( $N>1000$ participants) and longer-term trials (at least 2 years), only the Finnish Geriatric Intervention Study to Prevent Cognitive Impairment and Disability (FINGER) reported significant intervention benefits on the primary and secondary cognitive outcomes [16]. The results from these 5 trials are difficult to compare directly due to substantial differences in, e.g., target populations, format and intensity of the interventions, and outcome measures. However, several characteristics specific for the FINGER intervention model have been emphasized as potential reasons behind its cognitive benefits [25]: (i) selection of an at-risk older population (60-77 years) based on the validated Cardiovascular Risk Factors, Aging and Dementia (CAIDE) Risk Score [26]; (ii) multidomain intervention covering five domains, i.e., diet, exercise, cognitive training, social activities, and monitoring of vascular/metabolic risk; and (iii) more intensive intervention, e.g., inclusion of an exercise program at the gym in addition to advice on physically active lifestyle and inclusion of both individual and group sessions to ensure sufficient support and motivation for healthy lifestyle changes.

\section{Risk stratification in multidomain intervention trials}

A cursory look at the mixed findings shown in Table 2 may tempt clinicians into thinking that the multidomain intervention concept is not as promising as initially hypothesized. However, the differences in the design between larger, longer-term trials that met vs. did not meet their primary outcomes suggest that multidomain intervention effectiveness may be highly dependent on a precision prevention approach, i.e., successfully identifying the at-risk groups who are most likely to benefit. To further investigate this, another literature search was conducted focusing on sub-group analyses assessing the 
Table 2 Overview of multidomain intervention trials for the prevention of cognitive decline and dementia

\begin{tabular}{lllll}
\hline Study & Design and population & Multidomain intervention & Primary outcome & Main results \\
\hline The MAX trial & $N=126$ & Individual, home-based mental & Global cognitive change based & Physical plus mental activity \\
(Barnes et al., & Adults with cognitive & activity plus class-based physical & on a comprehensive & was associated with significant \\
2013) [11] & complaints, USA & activity -4 groups & neuropsychological test & improvements in global \\
& Age, 65+ years & 1. Intervention (mental activity & battery & cognitive function. \\
& Duration, 12 weeks & 2. exercise vs. & \\
& & (mental activity intervention + & \\
& exercise control) vs. & \\
& 3. Control + intervention & \\
& (mental activity control + & \\
& exercise intervention) vs. & \\
& 4. Control (mental activity + &
\end{tabular}

$\begin{array}{ll}\text { Alves et al., } & N=56 \\ 2013 \text { [12] } & \text { Healthy women, Brazil } \\ & \text { Mean age, 66.8 years } \\ & \text { Duration, 24 weeks }\end{array}$

Ihle-Hansen $\quad N=195$

et al., 2014 Patients after the first stroke,

[13]

Norway

Mean age, 71.6 years

Duration, 12 months

$\begin{array}{ll}\text { The SMART } & N=100 \\ \text { study } & \text { Adults with MCl, Australia } \\ \text { (Fiatarone } & \text { Mean age, } 70.1 \text { years } \\ \text { Singh et al., } & \text { Duration, } 18 \text { months }\end{array}$

$\begin{array}{ll}\text { Lam et al., } & N=555 \\ 2015 \text { [15] } & \text { Adults with MCl, Hong Kong } \\ & \text { Mean age, 75.4 years } \\ & \text { Duration, 18 months }\end{array}$

FINGER $\quad N=1260$

(Ngandu et al., Persons at-risk of dementia,

2015) [16] Finland

Age, 60 to 77 years

Duration, 2 years

ASPIS (Matz $\quad N=202$

et al., 2015) Stroke patients, Austria

[17] Age, 40 to 80 years

Duration, 2 years

$$
\text { exercise) }
$$

Creatine supplementation and exercise-4 groups

1. Creatine supplementation vs.

2. Placebo vs.

3. Creatine supplementation + strength training vs.

4. Placebo + strength training

Outpatient stroke nurse and physician consultation 3 and 6 months post-stroke, information about lifestyle and brain health.

Medical treatment optimized.

Tailored advice regarding risk

factor management and treatment plan sent to a general practitioner. Offered smoking cessation courses vs. care as usual

2 supervised interventions, 2-3 days/week for 6 months with

18 months follow-up

- Active OR sham physical training (high-intensity progressive resistance training vs. seated calisthenics) plus

- Active OR sham cognitive training (computerized, multidomain cognitive quizzes)

Physical exercise vs. Cognitive activity vs. Integrated cognitive and physical exercise vs. Social activity (active control) groups training vs. watching videos/

Cognitive function (memory, selective attention, and inhibitory control)

Trail-making test A and 10word test from baseline to 12 months follow-up

Global cognitive function (ADAS-Cog) and functional independence vascular risk monitoring) vs. general health advice

Multidomain intervention (clinical therapy, adequate blood pressure, lipid and glycaemic control, healthy diet, regular physical activity,
No significant effect on cognition.

No difference between the intervention and control groups.
Resistance training significantly improved global cognitive function, with the maintenance of executive and global benefits over 18 months.
Clinical Dementia Rating sum of boxes (CDR-SOB) scores

Cognition on the neuropsychological test battery

No difference between the groups for change in CDR-SOB and functional scores. Integrated physical and cognitive intervention exerted significantly better cognitive benefits on category verbal fluency test but not across all cognitive domains compared to single cognitive or physical activity intervention.

Significant intervention benefit on cognition.

Cognition on Alzheimer Disease Assessment Scale and neuropsychological test No difference between the intervention and control groups. 
Table 2 Overview of multidomain intervention trials for the prevention of cognitive decline and dementia (Continued)

\begin{tabular}{|c|c|c|c|c|}
\hline Study & Design and population & Multidomain intervention & Primary outcome & Main results \\
\hline & & $\begin{array}{l}\text { cognitive training) vs. standard } \\
\text { stroke care }\end{array}$ & & \\
\hline $\begin{array}{l}\text { preDIVA (Moll } \\
\text { van Charante } \\
\text { et al., 2016) } \\
{[18]}\end{array}$ & $\begin{array}{l}N=3526 \\
\text { Community-dwelling older } \\
\text { persons, the Netherlands } \\
\text { Age, } 70 \text { to } 78 \text { years } \\
\text { Duration, } 6 \text { years }\end{array}$ & $\begin{array}{l}\text { Multidomain intensive vascular } \\
\text { care vs. standard care }\end{array}$ & $\begin{array}{l}\text { Incident dementia and } \\
\text { disability score }\end{array}$ & $\begin{array}{l}\text { No difference between the } \\
\text { intervention and control } \\
\text { groups. }\end{array}$ \\
\hline $\begin{array}{l}\text { MAPT } \\
\text { (Andrieu et al., } \\
\text { 2017) [19] }\end{array}$ & $\begin{array}{l}N=1680 \\
\text { Community-dwelling older } \\
\text { persons, France } \\
\text { Mean age, } 75.3 \text { years } \\
\text { Duration, } 3 \text { years }\end{array}$ & $\begin{array}{l}\text { 1. Multidomain intervention + } \\
\text { omega-3 supplementation } \\
\text { 2. Multidomain intervention + } \\
\text { placebo } \\
\text { 3. Omega-3 supplementation } \\
\text { alone } \\
\text { 4. Placebo alone }\end{array}$ & $\begin{array}{l}\text { Cognitive decline on } \\
\text { composite } Z \text { score }\end{array}$ & $\begin{array}{l}\text { No difference between the } \\
\text { intervention and control } \\
\text { groups. }\end{array}$ \\
\hline $\begin{array}{l}\text { Look AHEAD } \\
\text { (Espeland } \\
\text { et al., 2018) } \\
\text { [20] }\end{array}$ & $\begin{array}{l}N=1091 \\
\text { Overweight or obese adults } \\
\text { with type } 2 \text { diabetes, USA } \\
\text { Age, } 45 \text { to } 76 \text { years } \\
\text { Duration, } 10 \text { years }\end{array}$ & $\begin{array}{l}\text { Lifestyle intervention (diet } \\
\text { modification and physical } \\
\text { activity) yielding long-term } \\
\text { weight loss vs. support and } \\
\text { education }\end{array}$ & $\begin{array}{l}\text { Change in cognition } \\
\text { (composite measure) }\end{array}$ & $\begin{array}{l}\text { No difference between the } \\
\text { intervention and control } \\
\text { groups. }\end{array}$ \\
\hline $\begin{array}{l}\text { KENKOJISEICH } \\
\text { (Bae et al., } \\
\text { 2019) [21] }\end{array}$ & $\begin{array}{l}N=83 \\
\text { Individuals with } \mathrm{MCl} \text {, Japan } \\
\text { Mean age, } 76 \text { years } \\
\text { Duration, } 24 \text { weeks }\end{array}$ & $\begin{array}{l}\text { Physical, cognitive, and social } \\
\text { activity sessions vs. health } \\
\text { education }\end{array}$ & $\begin{array}{l}\text { Cognition on the National } \\
\text { Center for Geriatrics and } \\
\text { Gerontology Functional } \\
\text { Assessment Tool }\end{array}$ & $\begin{array}{l}\text { Significant intervention effect } \\
\text { on spatial working memory. }\end{array}$ \\
\hline $\begin{array}{l}\text { Blumenthal } \\
\text { et al., } 2019 \\
{[22]}\end{array}$ & $\begin{array}{l}N=160 \\
\text { Older adults with cognitive } \\
\text { impairment and no dementia, } \\
\text { USA } \\
\text { Mean age, > } 55 \text { years } \\
\text { Duration, } 6 \text { months }\end{array}$ & $\begin{array}{l}\text { Diet and exercise-4 groups: } \\
\text { 1. Aerobic exercise vs. } \\
\text { 2. DASH diet nutritional } \\
\text { counseling vs. } \\
\text { 3. Combination of both aerobic } \\
\text { exercise and DASH vs. } \\
\text { 4. Health education }\end{array}$ & $\begin{array}{l}\text { Global measure of executive } \\
\text { cognitive functioning }\end{array}$ & $\begin{array}{l}\text { The largest improvements were } \\
\text { observed for combined aerobic } \\
\text { exercise and DASH diet group. }\end{array}$ \\
\hline $\begin{array}{l}\text { Body Brain } \\
\text { Life for } \\
\text { Cognitive } \\
\text { Decline } \\
\text { (McMaster } \\
\text { et al., 2020) } \\
\text { [23] }\end{array}$ & $\begin{array}{l}N=119 \\
\text { Subjective cognitive decline or } \\
\text { mild cognitive impairment, } \\
\text { Australia } \\
\text { Age, } 70 \text { to } 78 \text { years } \\
\text { Duration, } 8 \text { weeks }\end{array}$ & $\begin{array}{l}\text { Educational modules covering } \\
\text { dementia and lifestyle risk } \\
\text { factors, Mediterranean diet, } \\
\text { physical activity, and cognitive } \\
\text { engagement and additional } \\
\text { active components: dietitian } \\
\text { sessions, an exercise } \\
\text { physiologist session, and online } \\
\text { brain training vs. } 4 \text { online } \\
\text { informational modules to } \\
\text { reduce dementia risk }\end{array}$ & $\begin{array}{l}\text { Dementia risk using the } \\
\text { Australian National University- } \\
\text { Alzheimer's Disease Risk Index } \\
\text { (ANU-ADRI) and cognition }\end{array}$ & $\begin{array}{l}\text { The intervention group showed } \\
\text { a significantly lower ANU-ADRI } \\
\text { score and a significantly higher } \\
\text { cognition score than the con- } \\
\text { trol group. }\end{array}$ \\
\hline $\begin{array}{l}\text { DO-HEALTH } \\
\text { (Bischoff- } \\
\text { Ferrari et al., } \\
\text { 2020) [24] }\end{array}$ & $\begin{array}{l}N=2157 \\
\text { Adults having no major health } \\
\text { events in the } 5 \text { years prior to } \\
\text { enrolment, sufficient mobility, } \\
\text { and good cognitive status, } \\
\text { Europe (Switzerland, France, } \\
\text { Germany, Portugal, and Austria) } \\
\text { Age, } 70 \text { years or older } \\
\text { Duration, } 3 \text { years }\end{array}$ & $\begin{array}{l}\text { Supplementation and } \\
\text { exercise-8 groups: } \\
\text { 1. } 2000 \text { IU/day of vitamin D3, } 1 \\
\text { g/day of omega-3s, and a } \\
\text { strength-training exercise pro- } \\
\text { gram vs. } \\
\text { 2. Vitamin D3 and omega-3s vs. } \\
\text { 3. Vitamin D3 and exercise vs. } \\
\text { 4. Vitamin D3 alone vs. } \\
\text { 5. Omega-3s and exercise vs. } \\
\text { 6. Omega-3s alone vs. } \\
\text { 7. Exercise alone vs. } \\
\text { 8. Placebo }\end{array}$ & $\begin{array}{l}6 \text { primary outcomes: change in } \\
\text { systolic and diastolic blood } \\
\text { pressure, Short Physical } \\
\text { Performance Battery (SPPB), } \\
\text { Montreal Cognitive } \\
\text { Assessment (MoCA), and } \\
\text { incidence rates of non- } \\
\text { vertebral fractures and } \\
\text { infections }\end{array}$ & $\begin{array}{l}\text { No statistically significant } \\
\text { benefits of any intervention } \\
\text { individually or in combination } \\
\text { for all } 6 \text { end points. }\end{array}$ \\
\hline
\end{tabular}

ADAS-Cog Alzheimer's Disease Assessment Scale-Cognitive Subscale, ANU-ADRI Australian National University Alzheimer's Disease Risk Index, ASPIS Austrian Polyintervention Study to Prevent Cognitive Decline After Ischemic Stroke, CDR-SOB Clinical Dementia Rating sum of boxes, DASH Dietary Approaches to Stop Hypertension, FINGER Finnish Geriatric Intervention Study to Prevent Cognitive Impairment and Disability, MAPT Multidomain Alzheimer Preventive Trial, MAX Mental Activity and eXercise, MoCA Montreal Cognitive Assessment, preDIVA Prevention of Dementia by Intensive Vascular Care, SMART Study of Mental and Resistance Training, SPPB Short Physical Performance Battery

potential modifiers for the intervention effect on cognition in the multidomain prevention trials listed in Table 2. Identified sub-group analyses were based primarily on the FINGER, Multidomain Alzheimer Preventive Trial (MAPT), and Prevention of Dementia by Intensive Vascular Care (preDIVA) trials. Several of these analyses 
were pre-specified in the trial protocols, while others were conducted post hoc. The results are summarized in Table 3.

In the FINGER trial, where participants were selected using the CAIDE Dementia Risk Score including age, sex, education, hypertension, hypercholesterolemia, obesity, and physical inactivity, the intervention seemed to be beneficial for cognition irrespective of further stratification by sociodemographic, cognitive, or cardiovascular factors [27]. Although participants with a higher LIfestyle for BRAin health (LIBRA) index at baseline had overall less cognitive improvement over time, this effect was not different between the intervention and control groups [29]. The LIBRA index is based on 12 modifiable risk factors [36] that partly overlap with those included in the CAIDE score, which may explain this result.

Interestingly, significant benefits on cognition were reported among participants in the MAPT trial with a CAIDE score $\geq 6$ points (the same cutoff used in FINGER) [34]. Other analyses stratified by frailty status found no differences in the intervention effect on cognition between frail and non-frail MAPT participants [32].

The LIBRA index did not identify high-risk individuals in whom the preDIVA intervention was beneficial [35]. However, preDIVA trial participants with untreated hypertension and who were adherent to the intervention had a significantly lower risk of dementia compared with the control group [18]. This is perhaps not surprising considering that the preDIVA intervention placed more weight on the cardiovascular risk management component compared with the lifestyle components. Participants without a history of cardiovascular disease who were adherent to the preDIVA intervention also had a significantly lower risk of dementia compared to the control group.

The impact of genetic factors on the intervention effects on cognition has been so far reported only in the FINGER and MAPT trials. No significant difference in the intervention-related cognitive benefits was observed between $A P O E$ \&4 allele carriers and non-carriers. However, analyses stratified by $A P O E \& 4$ carrier status showed a significant intervention-related cognitive benefit among the group of $\varepsilon 4$ carriers in FINGER [28], with a similar trend in MAPT [19]. In addition, a more pronounced cognitive benefit was reported in FINGER participants with shorter leukocyte telomere length at baseline, i.e., higher-risk individuals [30]. However, it would be particularly important for multidomain prevention trials to assess the impact of genetic risk beyond APOE genotype alone, e.g., via polygenic risk scores.

Brain imaging markers were also considered as potential intervention effect modifiers in the FINGER and MAPT trials. The MAPT intervention was reported to be associated with beneficial effects on cognition in individuals with amyloid positivity on positron emission tomography (PET) scans [33]. However, the FINGER intervention had more cognitive benefits in participants with higher brain volumes and cortical thickness at baseline [31]. It has been suggested that, while amyloid PET detects the early stages of amyloid deposition, morphological changes on MRI generally occur later in the Alzheimer's disease (AD) continuum [37]. In this context, the MAPT and FINGER findings emphasize that the best window of opportunity for precision risk reduction may be among individuals who have an increased dementia risk, but not yet substantial brain pathology and/ or substantial cognitive/functional impairment. In other words, earlier and better targeted multidomain interventions may be most effective.

\section{Estimating dementia risk reduction in early multidomain interventions}

The AD continuum is characterized by a long period (up to decades) between the start of brain pathology and dementia onset [38]. In early interventions targeting atrisk individuals without substantial impairment, and with clinical trial durations that only very rarely exceed 2-3 years, dementia is not a feasible trial outcome. In the absence of direct data on the impact of multidomain interventions on reduction in dementia incidence, other ways to estimate the risk reduction are needed. Multifactorial risk scores that provide standardized, evidencebased estimates for the risk of dementia may be particularly useful for this purpose and may also facilitate continuous monitoring of the intervention effects in practice by both clinicians and at-risk individuals.

Dementia risk scores have only recently started to be used in the context of prevention trials. For example, the FINGER trial used the CAIDE score for the recruitment of at-risk participants [16]. Several of the larger, longerterm multidomain intervention trials with cognition or dementia as primary outcomes are now also testing dementia risk scores as potential surrogate outcomes for estimating intervention effects on dementia risk reduction.

Table 4 summarizes the dementia risk scores used as outcome measures in multidomain prevention trials, including those where cognitive performance or dementia is not the primary outcome. Two smaller and shorterterm trials with younger individuals, Body Brain Life [23] and the In-MINDD feasibility trial [39], have used a dementia risk score as the primary outcome. In the larger and longer-term trials, dementia risk scores have been used as outcomes in post hoc analyses.

Overall, the results indicate significant intervention benefits on the tested dementia risk scores, supporting the potential use of these scores for estimating dementia risk reduction. However, estimates from such analyses 
Table 3 Examples of sub-group analyses assessing the potential modifiers for the intervention effect on cognition in multidomain prevention trials

\begin{tabular}{|c|c|c|c|c|}
\hline $\begin{array}{l}\text { Multidomain } \\
\text { trials }\end{array}$ & Study & Potential intervention effect modifiers & Analyses & Results \\
\hline \multirow[t]{5}{*}{ FINGER } & $\begin{array}{l}\text { Rosenberg } \\
\text { et al., } 2018 \\
\text { [27] }\end{array}$ & $\begin{array}{l}\text { Sex, age, education, socioeconomic status, } \\
\text { cognition, cardiovascular factors, and } \\
\text { cardiovascular comorbidity at baseline }\end{array}$ & $\begin{array}{l}\text { Pre- } \\
\text { specified }\end{array}$ & $\begin{array}{l}\text { No significant differences in cognitive intervention } \\
\text { benefits by sex, age, education, socioeconomic status, } \\
\text { cognition, cardiovascular factors, and cardiovascular } \\
\text { comorbidity. }\end{array}$ \\
\hline & $\begin{array}{l}\text { Solomon } \\
\text { et al., } 2018 \\
\text { [28] }\end{array}$ & APOE \&4 allele & $\begin{array}{l}\text { Pre- } \\
\text { specified }\end{array}$ & $\begin{array}{l}\text { Intervention benefits were not significantly different } \\
\text { between carriers and non-carriers. } \\
\text { Clear benefit in APOE } 4 \text { carriers in stratified analyses. }\end{array}$ \\
\hline & $\begin{array}{l}\text { Deckers et al., } \\
2020[29]\end{array}$ & LIBRA index at baseline & Post hoc & $\begin{array}{l}\text { Participants with a higher LIBRA index at baseline had } \\
\text { overall less cognitive improvement over time, but this } \\
\text { effect was not different between the intervention and } \\
\text { control groups. }\end{array}$ \\
\hline & $\begin{array}{l}\text { Sindi et al., } \\
2017 \text { [30] }\end{array}$ & Leukocyte telomere length & Post hoc & $\begin{array}{l}\text { More pronounced cognitive intervention benefits in } \\
\text { individuals with shorter baseline leukocyte telomere } \\
\text { length (higher-risk individuals). }\end{array}$ \\
\hline & $\begin{array}{l}\text { Stephen } \\
\text { et al., } 2019 \\
\text { [31] }\end{array}$ & Brain volumes and cortical thickness & Post hoc & $\begin{array}{l}\text { More pronounced cognitive intervention effects in } \\
\text { individuals with higher brain baseline cortical thickness } \\
\text { and volumes. }\end{array}$ \\
\hline \multirow[t]{5}{*}{ MAPT } & $\begin{array}{l}\text { Andrieu } \\
\text { et al., } 2017 \\
{[19]}\end{array}$ & Cognition and functioning level at baseline & $\begin{array}{l}\text { Pre- } \\
\text { specified }\end{array}$ & No significant differences in intervention effects. \\
\hline & $\begin{array}{l}\text { Andrieu } \\
\text { et al., } 2017 \\
{[19]}\end{array}$ & APOE $\varepsilon 4$ allele & Post.hoc & $\begin{array}{l}\text { Intervention effects were not significantly different } \\
\text { between carriers and non-carriers. }\end{array}$ \\
\hline & $\begin{array}{l}\text { Tabue-Teguo } \\
\text { et al., } 2018 \\
\text { [32] }\end{array}$ & Frailty status & Post hoc & $\begin{array}{l}\text { Beneficial effects of multidomain intervention and n3 } \\
\text { PUFA supplementation on cognition did not differ } \\
\text { between frail and non-frail participants. }\end{array}$ \\
\hline & $\begin{array}{l}\text { Delrieu et al., } \\
2019[33]\end{array}$ & Amyloid status & Post hoc & $\begin{array}{l}\text { Multidomain intervention alone or in combination with } \\
\text { omega-3 fatty acids was associated with improved pri- } \\
\text { mary cognitive outcomes in individuals with positive } \\
\text { amyloid status. }\end{array}$ \\
\hline & $\begin{array}{l}\text { Chhetri et al., } \\
2018 \text { [34] }\end{array}$ & CAIDE score $\geq 6$ points & Post hoc & $\begin{array}{l}\text { High-risk subjects for dementia screened with CAIDE } \\
\text { dementia score might benefit more from multidomain } \\
\text { intervention. }\end{array}$ \\
\hline \multirow[t]{3}{*}{ preDIVA } & $\begin{array}{l}\text { Moll van } \\
\text { Charante } \\
\text { et al., } 2016 \\
{[18]}\end{array}$ & Participants free from cardiovascular disease & $\begin{array}{l}\text { Pre- } \\
\text { specified }\end{array}$ & $\begin{array}{l}\text { Participants with a history free from cardiovascular } \\
\text { disease who were adherent to the intervention had a } \\
\text { significantly lower risk of dementia compared to the } \\
\text { control group. }\end{array}$ \\
\hline & $\begin{array}{l}\text { Moll van } \\
\text { Charante } \\
\text { et al., } 2016 \\
{[18]}\end{array}$ & Untreated hypertension at baseline & $\begin{array}{l}\text { Pre- } \\
\text { specified }\end{array}$ & $\begin{array}{l}\text { Participants with untreated hypertension who were } \\
\text { adherent to the intervention had a significantly lower } \\
\text { risk of dementia compared with the control group. }\end{array}$ \\
\hline & $\begin{array}{l}\text { van } \\
\text { Middelaar } \\
\text { et al., } 2018 \\
\text { [35] }\end{array}$ & LIBRA index at baseline & Post hoc & $\begin{array}{l}\text { LIBRA modifiable dementia risk score did not identify a } \\
\text { (high-)risk group in whom the multidomain intervention } \\
\text { was effective in preventing dementia or cognitive } \\
\text { decline. }\end{array}$ \\
\hline
\end{tabular}

Subgroup analysis type (pre-specified and post hoc) was assessed from published trial protocols

APOE apolipoprotein E, CAIDE Cardiovascular Risk Factors, Aging and Dementia, FINGER Finnish Geriatric Intervention Study to Prevent Cognitive Impairment and Disability, LIBRA LIfestyle for BRAin health, MAPT Multidomain Alzheimer Preventive Trial, preDIVA Prevention of Dementia by Intensive Vascular Care, PUFA polyunsaturated fatty acids

are currently difficult to interpret or compare between different risk scores and would have to be verified against direct data on dementia incidence following the intervention. A potential solution for this could be extended follow-ups of trial participants after the intervention is completed, e.g., via healthcare registries if not otherwise feasible.

\section{Dementia risk scores and brain pathology markers}

Although many dementia risk scores have been developed for predicting subsequent dementia or cognitive decline, only two have so far been tested in relation to brain pathology (e.g., cerebrospinal fluid (CSF) or neuroimaging biomarkers, or brain pathology at autopsy). Detailed knowledge on the performance of a dementia risk 
Table 4 Dementia risk scores used as surrogate outcomes in multidomain prevention trials

\begin{tabular}{|c|c|c|c|c|}
\hline Study & Trial & $\begin{array}{l}\text { Dementia } \\
\text { risk score }\end{array}$ & Outcome type & Main results \\
\hline $\begin{array}{l}\text { O'Donnell } \\
\text { et al., } 2015 \\
\text { [39] }\end{array}$ & $\begin{array}{l}\text { In- } \\
\text { MINDD }\end{array}$ & LIBRA & Primary & $\begin{array}{l}\text { Participants in both arms of the trial showed a small improvement in their LIBRA } \\
\text { score. The improvement was slightly larger in the intervention arm, but not } \\
\text { statistically significant after } 6 \text { months. }\end{array}$ \\
\hline $\begin{array}{l}\text { Solomon } \\
\text { et al., } 2018 \\
{[40]}\end{array}$ & FINGER & CAIDE & Post hoc & $\begin{array}{l}\text { The intervention had a significant impact on lowering the CAIDE risk score after } \\
2 \text { years. }\end{array}$ \\
\hline $\begin{array}{l}\text { Barbera et al., } \\
2020 \text { [41] }\end{array}$ & $\begin{array}{l}\text { FINGER } \\
\text { MAPT } \\
\text { PreDIVA }\end{array}$ & CAIDE & $\begin{array}{l}\text { Post hoc, individual } \\
\text { participants pooled } \\
\text { analysis }\end{array}$ & CAIDE score decreased significantly as a result of the interventions after 2 years. \\
\hline $\begin{array}{l}\text { Coley et al., } \\
2020 \text { [42] }\end{array}$ & $\begin{array}{l}\text { preDIVA } \\
\text { MAPT } \\
\text { HATICE }\end{array}$ & $\begin{array}{l}\text { LIBRA and } \\
\text { CAIDE }\end{array}$ & $\begin{array}{l}\text { Post hoc, each trial } \\
\text { analyzed separately }\end{array}$ & $\begin{array}{l}\text { CAIDE and LIBRA scores showed statistically significant between-group differences } \\
\text { after multidomain interventions after } 1.5 \text { to } 2 \text { years. }\end{array}$ \\
\hline $\begin{array}{l}\text { Deckers et al., } \\
2020[29]\end{array}$ & FINGER & LIBRA & Post hoc & $\begin{array}{l}\text { The intervention decreased dementia risk as indicated by decreasing LIBRA score } \\
\text { after } 2 \text { years. }\end{array}$ \\
\hline $\begin{array}{l}\text { McMaster } \\
\text { et al., } 2020 \\
\text { [23] }\end{array}$ & $\begin{array}{l}\text { Body } \\
\text { Brain } \\
\text { Life }\end{array}$ & ANU-ADRI & Primary & $\begin{array}{l}\text { Significant reduction in ANU-ADRI score for BBL compared with control after } 2 \\
\text { months. }\end{array}$ \\
\hline
\end{tabular}

ANU-ADRI Australian National - University Alzheimer's Disease Risk Index, CAIDE Cardiovascular Risk Factors, Aging and Dementia, FINGER Finnish Geriatric Intervention Study to Prevent Cognitive Impairment and Disability, HATICE Healthy Ageing Through Internet Counselling in the Elderly, In-MINDD Innovative Midlife Intervention for Dementia Deterrence, LIBRA LIfestyle for BRAin health, MAPT Multidomain Alzheimer Preventive Trial, preDIVA Prevention of Dementia by Intensive Vascular Care

score in predicting specific types of brain pathology (e.g., AD-related, or cerebrovascular) is essential for making informed decisions about the intervention study design, e.g., identification of the appropriate at-risk individuals who are most likely to benefit from a specific intervention, or monitoring of intervention effects on dementia risk reduction.

An English-language literature search was conducted using medical databases (MEDLINE via PubMed and SCOPUS, until December 2020) and keywords such as "dementia," "Alzheimer," "risk score," "risk algorithm," "biomarker," "MRI," "PET," and "pathology." The focus was on dementia risk scores including modifiable factors. A summary of the reported relations between dementia risk scores and brain pathology markers is shown in Table 5. The CAIDE score is so far the most extensively tested in relation to biomarkers, including CSF and neuroimaging markers (structural MRI and amyloid PET), and post-mortem brain pathology. The Australian National University Alzheimer's Disease Risk Index (ANU-ADRI) score has been tested in relation to MRI markers.

Although neuropathology markers can be used directly as predictors of dementia risk, currently available markers (CSF and neuroimaging) are more difficult to assess outside highly specialized memory clinic settings, and their use is not always recommended in a population of cognitively unimpaired individuals for ethical or health economics reasons [49]. Validating simpler and easier to use dementia risk scores in relation to neuropathology markers would thus offer more cost-effective solutions for early identification of at-risk individuals in a broader range of clinical settings, where risk reduction interventions can also be started earlier, before the onset of substantial impairment requiring referral for more invasive and costly diagnostic procedures.

Another key aspect to consider when choosing a dementia risk score for precision risk reduction is to what extent it captures risk versus prevention potential, i.e., room for improvement with intervention. Risk scores such as CAIDE, ANU-ADRI, or LIBRA include modifiable risk factors, thus indicating not only the risk profile, but also the intervention components that are needed to modify an individual's risk profile. It is currently unclear to what extent neuropathology markers could be used to estimate prevention potential, although they could be very useful as secondary outcomes in multidomain interventions that combine non-pharmacological approaches with disease-modifying drugs. Assessing the neuropathology markers in multidomain prevention trials could also provide valuable knowledge on the interplay between cognitive reserve and brain pathology in determining intervention outcomes.

\section{Dementia vs. cardiovascular risk reduction}

The 2019 WHO guidelines for risk reduction of cognitive decline and dementia also covered evidence on interventions targeted at reducing cardiovascular risk factors (e.g., hypertension, dyslipidemia, and diabetes) both pharmacologically and non-pharmacologically. The potential for integrating these recommendations into existing cardiovascular prevention programs was also emphasized. Although validated CVD risk scores have long been an established part of cardiovascular 
Table 5 Dementia risk scores in relation to brain pathology markers

\begin{tabular}{|c|c|c|c|}
\hline Risk score & Study design & Biomarkers & Findings \\
\hline \multicolumn{4}{|l|}{ CAIDE } \\
\hline $\begin{array}{l}\text { Vuorinen } \\
\text { et al., } 2015 \\
\text { [43] }\end{array}$ & $\begin{array}{l}\text { Cohort, general } \\
\text { population, Finland } \\
N=181 \\
\text { Mean age, } 50 \text { years } \\
\text { Follow-up, } 30 \text { years }\end{array}$ & $\begin{array}{l}\text { Brain cortical thickness, white matter lesions, } \\
\text { medial temporal atrophy on MRI }\end{array}$ & $\begin{array}{l}\text { Higher score associated with higher medial temporal } \\
\text { atrophy, white matter lesions, and lower cortical thickness } \\
\text { two to three decades later. }\end{array}$ \\
\hline $\begin{array}{l}\text { Enache } \\
\text { et al., } 2016 \\
\text { [44] }\end{array}$ & $\begin{array}{l}\text { Cohort, memory } \\
\text { clinic patients SCl } \\
\text { and } \mathrm{MCl} \text {, Sweden } \\
\mathrm{N}=724 \\
\text { Age, > } 40 \text { years } \\
\text { Follow-up, cross- } \\
\text { sectional }\end{array}$ & AD-related CSF markers & $\begin{array}{l}\text { Higher score associated with CSF markers of } \\
\text { neurodegeneration ( } \downarrow A \beta \text { and } \uparrow \text { total tau). }\end{array}$ \\
\hline $\begin{array}{l}\text { Stephen } \\
\text { et al., } 2017 \\
\text { [45] }\end{array}$ & $\begin{array}{l}\text { Cohort, at-risk for } \\
\text { dementia, Finland } \\
N=132 \\
\text { Age, 60-77 years } \\
\text { Follow-up, 20-30 } \\
\text { years }\end{array}$ & $\begin{array}{l}\text { Brain volumes and cortical thickness, medial } \\
\text { temporal atrophy, white matter lesions on MRI, } \\
\text { and amyloid positivity on PiB-PET }\end{array}$ & $\begin{array}{l}\text { Higher score associated with lower volumes and cortical } \\
\text { thickness, medial temporal atrophy, and white matter } \\
\text { lesions but not with amyloid on PiB-PET. }\end{array}$ \\
\hline $\begin{array}{l}\text { Hooshmand } \\
\text { et al., } 2018 \\
{[46]}\end{array}$ & $\begin{array}{l}\text { Cohort, without } \\
\text { dementia at } \\
\text { baseline, Finland } \\
N=149 \\
\text { Age, } \geq 85 \text { years } \\
\text { Follow-up, } 10 \text { years }\end{array}$ & Brain pathology at autopsy & $\begin{array}{l}\text { Higher score associated with increased cerebral } \\
\text { infractions. }\end{array}$ \\
\hline $\begin{array}{l}\text { O'Brien } \\
\text { et al., } 2019 \\
{[47]}\end{array}$ & $\begin{array}{l}\text { Cohort, middle-aged } \\
\text { healthy adults, UK } \\
N=149 \\
\text { Age, } 40-59 \text { years } \\
\text { Follow-up, } 2 \text { years }\end{array}$ & $\begin{array}{l}\text { Rate of change in brain and ventricular volumes } \\
\text { on MRI }\end{array}$ & $\begin{array}{l}\text { Higher score associated with progressive brain atrophy } \\
\text { rates. }\end{array}$ \\
\hline \multicolumn{4}{|l|}{ ANU-ADRI } \\
\hline $\begin{array}{l}\text { Cherbuin } \\
\text { et al., } 2019 \\
{[48]}\end{array}$ & $\begin{array}{l}\text { Cohort, individuals } \\
\text { free of dementia, } \\
\text { Australia } \\
N=461 \\
\text { Age, } 60-64 \text { years } \\
\text { Follow-up, } 12 \text { years }\end{array}$ & Total and regional brain volumes on MRI & $\begin{array}{l}\text { Higher score was associated with lower cortical gray } \\
\text { matter particularly in the default mode network. }\end{array}$ \\
\hline
\end{tabular}

$A \beta$ amyloid-beta, $A D$ Alzheimer's disease, $A N U$-ADRI Australian National University Alzheimer's Disease Risk Index, CSF cerebrospinal fluid, $M R I$ magnetic resonance imaging, PiB-PET Pittsburgh compound B-positron emission tomography, $M C I$ mild cognitive impairment, $S C l$ subjective cognitive impairment

prevention, the testing of CVD risk scores in the context of dementia prevention has only recently started.

For example, the Framingham CVD risk score includes age, sex, systolic blood pressure, treatment for hypertension, HDL cholesterol, total cholesterol, smoking, and diabetes. The Framingham stroke risk score combines age, systolic blood pressure, treatment for hypertension, diabetes, smoking, prior CVD (myocardial infarction, angina pectoris, coronary insufficiency, intermittent claudication, or congestive heart failure), atrial fibrillation, and left ventricular hypertrophy. Both versions of the Framingham risk score at midlife have been reported to predict cognitive decline and dementia [50]. Additionally, the Framingham CVD risk score has been reported to predict vascular dementia [51] and clinical progression in patients with AD dementia, particularly in those with genetic and atherosclerotic risk factors [52]. However, the Framingham CVD risk score was not associated with structural brain measures on MRI [53].

The Framingham CVD risk score and two dementia risk scores (CAIDE and Washington Heights-Inwood Columbia Aging Project (WHICAP)) were investigated in relation to cognitive performance in different ethnic groups [54]. All three scores were significantly associated with cognition in both Hispanic/Latino and nonHispanic/Latino populations.

Life's Simple 7 (LS7), defined by the American Heart Association as the 7 risk factors modifiable through lifestyle changes that can help achieve ideal cardiovascular health [55], has also been proposed as a potential tool for dementia risk reduction. The LS7 risk score includes four behavioral (smoking, diet, physical activity, body mass index) and three biological (fasting glucose, cholesterol, and blood pressure) factors. A lower LS7 score indicating poorer CVD health has been associated with a 
higher risk of dementia in a long-term (25 years) observational study, while adherence to the LS7 ideal cardiovascular health recommendations in midlife has been linked to lower dementia risk [56]. Another CVD risk score including age, systolic blood pressure, total cholesterol, high-density lipoprotein, smoking, body mass index, and diabetes has been suggested as a useful tool for identifying individuals at risk for cognitive decline and dementia [57].

The global vascular risk score (GVRS) was developed to test whether the addition of behavioral and anthropometric risk factors to traditional vascular risk factors can improve the prediction of clinical vascular events (e.g., stroke and myocardial infarction). The score combines age, sex, ethnicity, waist, alcohol consumption, smoking, physical activity, blood pressure, antihypertensive medication, peripheral vascular disease, blood glucose, and cholesterol. The GVRS has been associated with cognition, e.g., decline in global cognition, episodic memory, and processing speed over time, although this association seemed to be more pronounced in APOE $\varepsilon 4$ non-carriers [58]. The GVRS has been suggested as a feasible tool for use in primary care settings [59].

All the abovementioned studies have been observational. So far, only one study has investigated the CVD risk scores in the context of clinical trials for dementia prevention, reporting that multidomain interventions designed for dementia risk reduction significantly improved CVD risk scores such as FINRISK and SCORE [41].

Although CVD risk scores seem promising as potential tools for dementia risk reduction, their testing and validation for this purpose are still far from the standards available in the field of cardiovascular prevention. An important issue is the longer-vs. shorter-term prediction of dementia risk. Studies on dementia risk scores have clearly shown that risk profiles in midlife can be very different from risk profiles at older ages, and especially in older individuals who are already closer to dementia onset [60]. The time between the onset of brain pathology and the onset of clinical symptoms is also the time when "silent disease" can affect a variety of vascular, metabolic, and lifestyle factors, i.e., reverse causality. This is the most likely reason why shorter-term observational studies $(<5$ years $)$ in older populations often report associations between factors such as low blood pressure, low BMI, or low cholesterol and increased likelihood of dementia $[60,61]$. Such findings likely indicate markers on an ongoing dementia-related disease and not actual risk factors. It is currently unclear if and to what extent CVD risk scores can be applied in older populations. Their associations with different types of brain pathology are also not yet determined.

\section{Discussion}

Dementia prevention is still relatively new compared with, e.g., cardiovascular prevention, and much work is still left to be done to reach the standards of evidence and level of organization for pragmatic CVD risk reduction programs. Emerging evidence from recent multidomain prevention trials indicates that optimal preventive effects may be obtained through a precision risk reduction approach, i.e., targeting an individual's overall risk profile instead of separate risk factors, and tailoring the right interventions to the right people at the right time. Randomized controlled trials testing early dementia risk reduction interventions have an inherent design complexity that CVD trials do not have to deal with, particularly in terms of outcome definitions. While CVD outcomes targeted by preventive interventions tend to be acute, clearly identifiable events, this is not the case for outcomes related to dementia diseases that are chronic, slowly progressive, often insidious, and requiring more specialized assessments to detect (e.g., neuroimaging, CSF). In addition, it is not fully clear how much intervention exposure and in what format would be necessary for achieving optimal effects, or at least what minimal level of exposure would be needed for some benefit to still be derived from dementia risk reduction interventions. Moreover, since most of the multidomain interventions were conducted in high-income countries, it is not clear whether their results can be generalized to low- and middle-income countries and is therefore necessary to collect further evidence from different settings. Thus, longer-term randomized controlled trials are much needed to address these issues. One such example is World Wide-FINGERS (WW-FINGERS, currently about 35 member countries), the first global network for multimodal dementia prevention trials, where the FINGER intervention model is currently being tested, adapted, and optimized in different populations, and geographic and economic settings, and focus is also on data harmonization and joint planning of these worldwide trials [62]. A limitation of this review is that the literature search was conducted in the English language only, and other potentially relevant studies may have been missed.

An important point regarding the development and testing of dementia and/or CVD risk scores in the context of dementia risk reduction concerns how findings are reported in the literature. Standardized and transparent reporting is crucial to facilitate decision-making about the choice of the most suitable risk estimation tools for specific purposes. The TRIPOD statement (transparent reporting of a multivariable prediction model for individual prognosis or diagnosis) [63] was published in 2015, and these guidelines would need to be followed similarly to for example CONSORT 
guidelines for reporting clinical trials, or STROBE guidelines for reporting cohort studies.

\section{From research to implementation}

Most risk reduction interventions have been conducted in a research setting. BHSs will allow to implement the risk reduction interventions in the real world by offering the opportunity for cognitively unimpaired users to actively act and reduce their chances of developing dementia in the future. Before implementing the risk reduction interventions, an accurate dementia risk profiling (assessing the genetic, lifestyle, and biological risk factors; [7]) is needed to tailor the interventions to individual BHS users.

The 2019 WHO guidelines for risk reduction of cognitive decline and dementia [3] have emphasized that the implementation of interventions for cardiovascular and lifestyle risk factors may be combined with existing for example CVD or diabetes prevention programs and targeted to relevant populations. For this purpose, it is

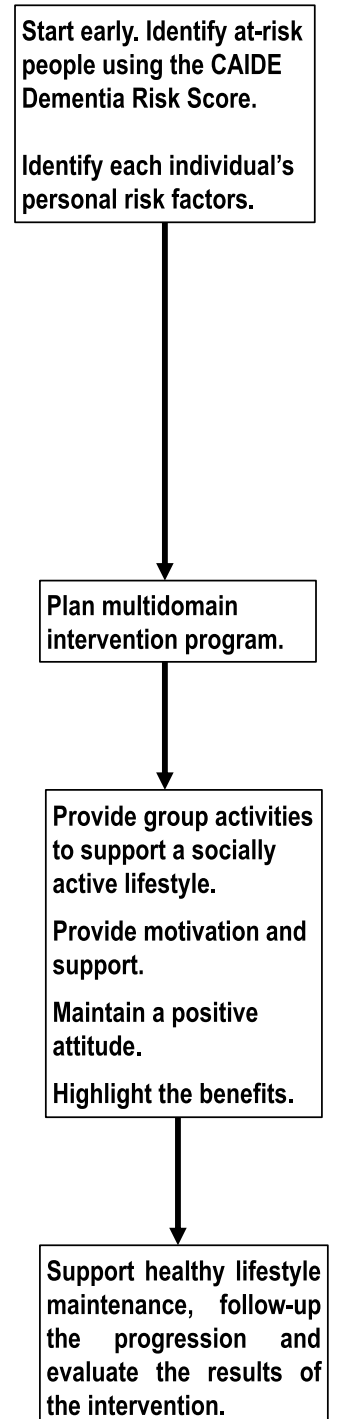

the intervention.

\begin{tabular}{lll}
\hline Factors & \multicolumn{2}{c}{ Points } \\
\hline \multirow{2}{*}{ Age, years } & $<47$ & 0 \\
& $47-53$ & 3 \\
& $>53$ & 4 \\
Education, years & $\geq 10$ & 0 \\
& $7-9$ & 2 \\
Sex & $0-6$ & 3 \\
& Women & 0 \\
Systolic BP, $\mathrm{mmHg}$ & Men & 1 \\
& $\leq 140$ & 0 \\
BMI, kg/m² & $>140$ & 2 \\
& $\leq 30$ & 0 \\
Total cholesterol, $\mathrm{mmol} / / \mathrm{l}$ & -6.5 & 0 \\
& $>6.5$ & 2 \\
Physical activity & Active & 0 \\
& Inactive & 1 \\
\hline
\end{tabular}

If the score is $\geq 6$ points, the person should be encouraged to participate in the multidomain intervention program.

Different people may have different risk profiles, and it is important to consider individual needs and goals. Due to the multifactorial nature of dementia, several risk factors may need to be targeted simultaneously. The main FINGER intervention components are summarized below:

\section{Strength training and aerobic exercise}

Diverse physical activity should include both muscle training at the gym (1-3 times/week) and aerobic exercise (2-5 times/week). Training should be individually tailored and progressive. Exercises to improve postural balance should be included. It is important to select exercises that motivate and support mental wellbeing and social activity. Safety issues should be taken into account.

\section{Healthy dietary habits}

To support a brain healthy diet, it is important to recommend high consumption of fruits and vegetables, consumption of whole grain cereal products, and low-fat milk and meat products, limiting of sugar and salt intake, use of vegetable margarine instead of butter, and fish consumption at least 2 portions/week. Even small changes can make a difference.

\section{Cognitive activity}

Memory needs long-term, regular and challenging activity. Learning new things, engaging in hobbies that also support mental wellbeing and social activity are good for the brain. Listening to and playing music, learning new languages, reading and playing games are all cognitive stimulating activities.

\section{Monitoring cardiovascular risk factors}

Management of cardiovascular and metabolic risk factors should follow national evidence-based guidelines. Regular measurement of blood pressure, blood sugar and cholesterol levels are recommended.

\section{My risk score and date


crucial that healthcare staff are fully aware of the importance of prevention in general and dementia prevention in particular. A recent survey highlighted that about $62 \%$ of the healthcare professionals did not consider dementia as a disorder but a condition of normal aging [64]. For effective implementation of prevention programs, a resource-efficient way may be to combine dementia prevention with cardiovascular prevention which is substantially more advanced in knowledge, research, and implementation compared to the more recent field of dementia prevention. Also, shared risk factors between the two diseases can help the use of existing knowledge and services to advance the idea of dementia prevention from research to practice.

Engaging participants actively and in a meaningful manner is important in implementing prevention interventions. Large, longer-term multidomain intervention trials for dementia risk reduction have already shown that such interventions are feasible $[16,18,19]$. The first template for an operational model for dementia risk reduction has also been developed following the FINGER trial (Fig. 1). Although several factors such as higher age, poorer cognition, depressive symptoms, and smoking have been reported to be associated with lower adherence to multidomain interventions, results vary across the trials and different intervention components [65, 66]. Individually tailored approaches to risk reduction may also be more likely to ensure adherence. For example, a person at-risk may be compliant to a healthy diet but may need support with physical and cognitive activities, or another person with diabetes may need extra support for diet and management of other cardiovascular risk factors.

Initiating and maintaining healthy lifestyle changes in general are challenging at a personal level and is impacted by factors such as participants' knowledge, access to facilities, time management, preference, and attitude towards prevention. Another layer of complexity is added especially when considering the implementation of such interventions or programs in low- and middleincome countries where prevention at mid-life may not be deemed as important as perceived in the Western world. Rosenberg et al. [67] recently studied the reasons for participation in a European multinational, multidomain eHealth lifestyle prevention trial (HATICE) targeting at-risk older adults without significant cognitive impairment. The participants were asked to specify the reasons for participation in the trial to which most responded: the desire to contribute to scientific progress, the possibility to improve their own health through lifestyle changes, and access to additional medical monitoring in the trial. Whether these same reasons motivate persons from other cultures and countries to participate and adhere to lifestyle interventions remains to be ascertained.
Therefore, it is important to identify the motivating factors, participants' expectation, and extending support to them or their active participation. Some motivating factors for participants to join and engage in prevention programs could be personal goal setting for the maintenance of participants' current and future health and avoidance of disability or dependency later in life [67]. Knowing their expectation during and after the participation would help educate them and gauge their goals and expectations realistically and for this those who are, e.g., at higher risk or lagging in motivation, to offer them extra support.

\section{Conclusion}

Evidence on the efficacy of risk reduction interventions is promising, but not yet conclusive. More long-term multidomain randomized controlled trials are needed to fill the current evidence gaps, and the WW-FINGERS points in this direction. Nevertheless, consistent evidence suggests that a precision risk reduction approach may be most effective for dementia prevention. Such an approach can be implemented in BHSs.

\section{Abbreviations}

WHO: World Health Organization; CVD: Cardiovascular conditions; BHS: Brain Health Services

\section{Acknowledgements}

European Task Force for Brain Health Services (in alphabetical order): Marc Abramowicz, Daniele Altomare, Frederik Barkhof, Marcelo Berthier, Melanie Bieler, Kaj Blennow, Carol Brayne, Andrea Brioschi, Emmanuel Carrera, Gael Chételat, Chantal Csajka, Jean-François Demonet, Alessandra Dodich, Bruno Dubois, Giovanni B. Frisoni, Valentina Garibotto, Jean Georges, Samia Hurst, Frank Jessen, Miia Kivipelto, David Llewellyn, Laura Mcwhirter, Richard Milne, Carolina Minguillón, Carlo Miniussi, José Luis Molinuevo, Peter M Nilsson, Janice Ranson, Federica Ribaldi, Craig Ritchie, Philip Scheltens, Alina Solomon, Cornelia van Duijn, Wiesje van der Flier, Bruno Vellas, and Leonie Visser.

\section{Authors' contributions}

Alina Solomon, Ruth Stephen, Philip Scheltens, and Miia Kivipelto conceptualized this paper, drafted the manuscript for intellectual content, and approved the final manuscript. Emmanuel Carrera, Jenni Kulmala, José Luis Molinuevo, Peter Nilsson, Tiia Ngandu, and Bruno Vellas revised the manuscript for intellectual content and approved the final manuscript. Daniele Altomare, Giovanni B. Frisoni, and Federica Ribaldi conceived and organized the workshop whence the papers of the BHS series in this issue of Alzheimer's Research \& Therapy originated, conceived the related editorial initiative, revised this manuscript for intellectual content, harmonized the manuscript with the other papers of the BHS series, and approved the final manuscript.

\section{Funding}

This paper was the product of a workshop funded by the Swiss National Science Foundation entitled "Dementia Prevention Services" (grant number: IZSEZO_193593).

AS receives research funding from the European Research Council grant 804371, Academy of Finland (287490, 294061, 319318), Yrjö Jahnsson

Foundation, Finnish Cultural Foundation (Finland), Alzheimerfonden, and Region Stockholm ALF (Sweden).

GBF received funding from the EU-EFPIA Innovative Medicines Initiatives 2 Joint Undertaking (IMI 2 JU): "European Prevention of Alzheimer's Dementia consortium" (EPAD, grant agreement number: 115736and "Amyloid Imaging to Prevent Alzheimer's Disease" (AMYPAD, grant agreement number:

115952), and the Swiss National Science Foundation: "Brain connectivity and 
metacognition in persons with subjective cognitive decline (COSCODE): cor relation with clinical features and in vivo neuropathology" (grant number: 320030_182772)

MK receives research funding from the Joint Programme -

Neurodegenerative Disease Research (EURO-FINGERS), Academy of Finland (305810, 317465), Swedish Research Council, Center for Innovative Medicine (CIMED) at Karolinska Institutet, Region Stockholm (ALF, NSV), Knut and Alice Wallenberg Foundation, Stiftelsen Stockholms Sjukhem, Konung Gustaf V:S och Drottning Victorias Frimurarstiftelse, Swedish Research Council for Health, and Working Life and Welfare (FORTE).

\section{Availability of data and materials}

Data sharing is not applicable to this article as no datasets were generated or analyzed during the current study.

\section{Declarations}

\section{Ethics approval and consent to participate}

Not applicable.

\section{Consent for publication}

Not applicable.

\section{Competing interests}

GBF reports grants from Alzheimer Forum Suisse, Académie Suisse des Sciences Médicales, Avid Radiopharmaceuticals, Biogen, GE International, Guerbert, Association Suisse pour la Recherche sur l'Alzheimer, IXICO, Merz Pharma, Nestlé, Novartis, Piramal, Roche, Siemens, Teva Pharmaceutical Industries, Vifor Pharma, and Alzheimer's Association; he has received personal fees from AstraZeneca, Avid Radiopharmaceuticals, Elan Pharmaceuticals, GE International, Lundbeck, Pfizer, and TauRx Therapeutics. JLM is currently a full-time employee of Lundbeck, has previously served as a consultant or at advisory boards for the following for-profit companies, or has given lectures in symposia sponsored by the following for-profit companies: Roche Diagnostics, Genentech, Novartis, Lundbeck, Oryzon, Biogen, Lilly, Janssen, Green Valley, MSD, Eisai, Alector, BioCross, GE Healthcare, and ProMIS Neurosciences.

PS has received consultancy fees (paid to the institution) from AC Immune, Alkermes, Alnylam, Anavex, Biogen, Brainstorm Cell, Cortexyme, Denali, EIP, ImmunoBrain Checkpoint, GemVax, Genentech, Green Valley, Novartis, Novo Noridisk, PeopleBio, Renew LLC, and Roche. He is a PI of studies with AC Immune, CogRx, FUJl-film/Toyama, IONIS, UCB, and Vivoryon. He serves on the board of the Brain Research Center.

The other authors declare that they have no competing interests.

\footnotetext{
Author details

${ }^{1}$ Institute of Clinical Medicine, University of Eastern Finland, Kuopio, Finland. ${ }^{2}$ Division of Clinical Geriatrics, NVS, Karolinska Institutet, Stockholm, Sweden. ${ }^{3}$ Ageing Epidemiology Research Unit, School of Public Health, Imperial College London, London, UK. ${ }^{4}$ Laboratory of Neuroimaging of Aging (LANV IE), University of Geneva, Geneva, Switzerland. ${ }^{5}$ Memory Clinic, Geneva University Hospitals, Geneva, Switzerland. '5troke Center, Department of Neurology, University Hospitals and University of Geneva, Geneva, Switzerland. ${ }^{7}$ Department of Public Health Solutions, Public Health Promotion Unit, Finnish Institute for Health and Welfare, Helsinki, Finland. ${ }^{8}$ Faculty of Social Sciences, Tampere University, Tampere, Finland. ${ }^{9}$ Barcelonaßeta Brain Research Center (BBRC), Pasqual Maragall Foundation, Barcelona, Spain. ${ }^{10}$ Department of Clinical Sciences, Skåne University Hospital, Lund University, Malmö, Sweden. ${ }^{11}$ Laboratory of Alzheimer's Neuroimaging and Epidemiology (LANE), Saint John of God Clinical Research Centre, Brescia, Italy. ${ }^{12}$ Department of Molecular and Translational Medicine, University of Brescia, Brescia, Italy. ${ }^{13}$ Gérontopole of Toulouse, University Hospital of Toulouse (CHU-Toulouse), Toulouse, France. ${ }^{14}$ Alzheimer Center Amsterdam, Department of Neurology, Amsterdam Neuroscience, Vrije Universiteit Amsterdam, Amsterdam UMC, Amsterdam, The Netherlands. ${ }^{15}$ Institute of Public Health and Clinical Nutrition, University of Eastern Finland, Kuopio, Finland.
}

Received: 28 January 2021 Accepted: 6 July 2021 Published online: 11 October 2021

\section{References}

1. Frisoni GB, Molinuevo JL, Altomare D, Carrera E, Barkhof F, Berkhof J, et al. Precision prevention of Alzheimer's and other dementias: anticipating future needs in the control of risk factors and implementation of diseasemodifying therapies. Alzheimer's Dement. 16:1457-68 Wiley; 2020 [cited 2020 Nov 24]. Available from: https://pubmed.ncbi.nlm.nih.gov/32815289/.

2. Livingston G, Huntley J, Sommerlad A, Ames D, Ballard C, Banerjee S, et al. Dementia prevention, intervention, and care: 2020 report of the Lancet Commission. Lancet. 2020:413-46 Lancet Publishing Group; [cited 2020 Sep 29]. https://doi.org/10.1016/S0140-6736(20)30367-6.

3. Risk reduction of cognitive decline and dementia: WHO guidelines. Geneva: World Health Organization; 2019. Licence: CC BY-NC-SA 3.0 IGO.

4. Hou X-H, Feng L, Zhang C, Cao X-P, Tan L, Yu J-T. Models for predicting risk of dementia: a systematic review. J Neurol Neurosurg Psychiatry. 2019;90(4): 373-9. https://doi.org/10.1136/jnnp-2018-318212.

5. Karmali KN, Persell SD, Perel P, Lloyd-Jones DM, Berendsen MA, Huffman MD. Risk scoring for the primary prevention of cardiovascular disease. Cochrane Database Syst Rev. Wiley; 2017 [cited 2020 Nov 23]. Available from: http://doi.wiley.com/10.1002/14651858.CD006887.pub4.

6. Altomare D, Molinuevo JL, Ritchie C, Ribaldi F, Carrera E, Dubois B, Jessen F, McWhirter L, Scheltens $P$, van der Flier WM, Vellas B, Démonet JF, Frisoni GB. Brain Health Services: Organization, structure and challenges for implementation. A user manual for Brain Health Services - Part 1 of 6. Alzheimer's Res Ther. 2021. https://doi.org/10.1186/s13195-021-00827-2.

7. Ranson JM, Rittman T, Hayat S, Brayne C, Jessen F, Blennow K, van Duijn C, Barkhof F, Tang E, Mummery CJ, Stephan BCM, Altomare D, Frisoni GB, Ribaldi F, Molinuevo JL, Scheltens P, Llewellyn, DJ. Modifiable risk factors for dementia and dementia risk profiling. A user manual for Brain Health Services - Part 2 of 6. Alzheimer's Res Ther. 2021. https://doi.org/10.1186/ s13195-021-00895-4.

8. Visser LNC, Minguillon C, Sánchez-Benavides G, Abramowicz M, Altomare D, Fauria K, Frisoni GB, Georges J, Ribaldi F, Scheltens P, van der Schaar J, Zwan M, van der Flier WM, Molinuevo JL. Dementia risk communication. A user manual for Brain Health Services - Part 3 of 6 . Alzheimer's Res Ther. 2021. https://doi.org/10.1186/s13195-021-00840-5.

9. Brioschi Guevara A, Bieler M, Altomare D, Berthier M, Csajka C, Dautricourt S, Démonet JF, Dodich A, Frisoni GB, Miniussi C, Molinuevo JL, Ribaldi F, Scheltens $P$, Chételat G. Protocols for cognitive enhancement. A user manual for Brain Health Services - Part 5 of 6. Alzheimer's Res Ther. 2021. https://doi.org/10.1186/s13195-021-00844-1.

10. Milne R, Altomare D, Ribaldi F, Molinuevo JL, Frisoni GB, Brayne C. Societal and equity challenges for Brain Health Services. A user manual for Brain Health Services - Part 6 of 6 . Alzheimer's Res Ther. 2021. https://doi.org/1 0.1186/s13195-021-00885-6.

11. Barnes DE, Santos-Modesitt W, Poelke G, Kramer AF, Castro C, Middleton LE, et al. The mental activity and exercise (MAX) trial: a randomized controlled trial to enhance cognitive function in older adults. JAMA Intern Med. 2013; 173:797-804 [cited 2020 Nov 23]. Available from: https://pubmed.ncbi.nlm. nih.gov/23545598/.

12. Alves CRR, Merege Filho CAA, Benatti FB, Brucki S, Pereira RMR, de Sá Pinto $A L$, et al. Creatine supplementation associated or not with strength training upon emotional and cognitive measures in older women: a randomized double-blind study. Blachier F, editor. PLoS One. 2013;8:e76301 Public Library of Science; [cited 2020 Dec 10]. Available from: https://dx.plos.org/1 0.1371/journal.pone.0076301.

13. Ihle-Hansen $H$, Thommessen B, Fagerland MW, Øksengård AR, Wyller TB, Engedal $\mathrm{K}$, et al. Multifactorial vascular risk factor intervention to prevent cognitive impairment after stroke and TIA: a 12-month randomized controlled trial. Int J Stroke. 2014;9:932-8 Blackwell Publishing Ltd; [cited 2020 Nov 23]. Available from: https://pubmed.ncbi.nlm.nih.gov/23205666/.

14. Fiatarone Singh MA, Gates N, Saigal N, Wilson GC, Meiklejohn J, Brodaty H, et al. The Study of Mental and Resistance Training (SMART) Study-resistance training and/or cognitive training in mild cognitive impairment: a randomized, double-blind, double-sham controlled trial. J Am Med Dir Assoc. 2014;15:873-80 Elsevier Inc.; [cited 2020 Nov 23]. Available from: https://pubmed.ncbi.nlm.nih.gov/25444575/.

15. Lam LC, Chan WC, Leung T, Fung AW, Leung EM. Would older adults with mild cognitive impairment adhere to and benefit from a structured lifestyle 
activity intervention to enhance cognition?: a cluster randomized controlled trial. PLoS One. 2015;10(3):e0118173. https://doi.org/10.1371/journal.pone. 0118173.

16. Ngandu T, Lehtisalo J, Solomon A, Levälahti E, Ahtiluoto S, Antikainen R, et al. A 2 year multidomain intervention of diet, exercise, cognitive training, and vascular risk monitoring versus control to prevent cognitive decline in at-risk elderly people (FINGER): a randomised controlled trial. Lancet. 2015; 385(9984):2255-63. https://doi.org/10.1016/S0140-6736(15)60461-5.

17. Matz K, Teuschl Y, Firlinger B, Dachenhausen A, Keindl M, Seyfang $L$, et al. Multidomain lifestyle interventions for the prevention of cognitive decline after ischemic stroke randomized trial. Stroke. 2015;46:2874-80 Lippincott Williams and Wilkins; [cited 2020 Sep 29]. Available from: https://pubmed. ncbi.nlm.nih.gov/26374482/.

18. van Charante EPM, Richard E, Eurelings LS, van Dalen JW, Ligthart SA, van Bussel EF, et al. Effectiveness of a 6-year multidomain vascular care intervention to prevent dementia (preDIVA): a cluster-randomised controlled trial. Lancet. 2016:388:797-805 Lancet Publishing Group.

19. Andrieu S, Guyonnet S, Coley N, Cantet C, Bonnefoy M, Bordes S, et al. Effect of long-term omega 3 polyunsaturated fatty acid supplementation with or without multidomain intervention on cognitive function in elderly adults with memory complaints (MAPT): a randomised, placebo-controlled trial. Lancet Neurol. 2017;16(5):377-89. https://doi.org/10.1016/S1474-4422 (17)30040-6 Lancet Publishing Group.

20. Espeland MA, Lipska K, Miller ME, Rushing J, Cohen RA, Verghese J, et al. Effects of physical activity intervention on physical and cognitive function in sedentary adults with and without diabetes. J Gerontol A Biol Sci Med Sci. 2017;72:861-6 [cited 2020 Sep 30]. Available from: https://pubmed.ncbi.nlm. nih.gov/27590629/.

21. Bae S, Lee S, Lee S, Jung S, Makino K, Harada K, et al. The effect of a multicomponent intervention to promote community activity on cognitive function in older adults with mild cognitive impairment: a randomized controlled trial. 2018; Available from: www.elsevier.com/locate/ctim

22. Blumenthal JA, Smith PJ, Mabe S, Hinderliter A, Lin PH, Liao L, et al. Lifestyle and neurocognition in older adults with cognitive impairments: a randomized trial. Neurology. 2019;92:E212-23 Lippincott Williams and Wilkins. [cited 2020 Dec 10]. Available from: https://n.neurology.org/ content/92/3/e212.

23. McMaster M, Kim S, Clare L, Torres SJ, Cherbuin N, D’Este C, et al. Lifestyle risk factors and cognitive outcomes from the multidomain dementia risk reduction randomized controlled trial, body brain life for cognitive decline (BBL-CD). J Am Geriatr Soc. 2020:jgs.16762 Blackwell Publishing Inc.;[cited 2020 Sep 29] Available from: https://onlinelibrary.wiley.com/doi/10.1111/jgs.16762.

24. Bischoff-Ferrari HA, Vellas B, Rizzoli R, Kressig RW, Da Silva JAP, Blauth M, et al. Effect of vitamin D supplementation, omega-3 fatty acid supplementation, or a strength-training exercise program on clinical outcomes in older adults: the DO-HEALTH randomized clinical trial. JAMA. 2020:324:1855-68 American Medical Association; [cited 2020 Dec 9]. Available from: https://pubmed.ncbi.nlm.nih.gov/33170239/.

25. Kulmala J, Ngandu T, Kivipelto M. Prevention matters: time for global action and effective implementation. J Alzheimer's Dis. 2018:S191-8 IOS Press; [cited 2020 Nov 23]. Available from: https://pubmed.ncbi.nlm.nih.gov/29504541/.

26. Kivipelto M, Ngandu T, Laatikainen T, Winblad B, Soininen H, Tuomilehto J. Risk score for the prediction of dementia risk in 20 years among middle aged people: a longitudinal, population-based study. Lancet Neurol. 2006; 5(9):735-41. https://doi.org/10.1016/S1474-4422(06)70537-3.

27. Rosenberg A, Ngandu T, Rusanen M, Antikainen R, Backman L, Havulinna S, et al. Multidomain lifestyle intervention benefits a large elderly population at risk for cognitive decline and dementia regardless of baseline characteristics: the FINGER trial. Alzheimers Dement. 2018;14:263-70. https:// doi.org/10.1016/j.jalz.2017.09.006.

28. Solomon A, Turunen H, Ngandu T, Peltonen M, Levälahti E, Helisalmi S, et al. Effect of the apolipoprotein e genotype on cognitive change during a multidomain lifestyle intervention a subgroup analysis of a randomized clinical trial. JAMA Neurol. 2018;75:462-70 American Medical Association; [cited 2020 Nov 23]. Available from: https://pubmed.ncbi.nlm.nih.gov/293 $56827 /$.

29. Deckers K, Köhler S, Ngandu T, Antikainen R, Laatikainen T, Soininen $H$, Strandberg T, Verhey F, Kivipelto M, Solomon A. Quantifying dementia prevention potential in the FINGER randomized controlled trial using the LIBRA prevention index. Alzheimers Dement. 2021;17(7):1205-12. https://doi. org/10.1002/alz.12281. Epub 2021 Jan 6
30. Sindi S, Ngandu T, Hovatta I, K'areholt I, Antikainen R, Hänninen T, et al. Baseline telomere length and effects of a multidomain lifestyle intervention on cognition: the FINGER randomized controlled trial. J Alzheimer's Dis. 2017;59:1459-70 IOS Press; [cited 2020 Nov 23]. Available from: https:// pubmed.ncbi.nlm.nih.gov/28777749/.

31. Stephen R, Liu Y, Ngandu T, Antikainen R, Hulkkonen J, Koikkalainen J, Kemppainen N, Lötjönen J, Levälahti E, Parkkola R, Pippola P, Rinne J, Strandberg T, Tuomilehto J, Vanninen R, Kivipelto M, Soininen $H$, Solomon A; FINGER study group. Brain volumes and cortical thickness on MRI in the Finnish Geriatric Intervention Study to Prevent Cognitive Impairment and Disability (FINGER). Alzheimers Res Ther. 2019;11(1):53. https://doi.org/10.11 86/s13195-019-0506-z.

32. Tabue-Teguo M, Barreto de Souza $P$, Cantet C, Andrieu S, Simo N, Fougère $B$, et al. Effect of multidomain intervention, omega-3 polyunsaturated fatty acids supplementation or their combinaison on cognitive function in nondemented older adults according to frail status: results from the MAPT Study. J Nutr Heal Aging. 2018;22:923-7 Springer-Verlag France; [cited 2020 Nov 23]. Available from: https://pubmed.ncbi.nlm.nih.gov/30272094/.

33. Delrieu J, Payoux P, Carrié I, Cantet C, Weiner M, Vellas B, et al. Multidomain intervention and/or omega-3 in nondemented elderly subjects according to amyloid status. Alzheimer's Dement. 2019;15:1392-401 Elsevier Inc.; [cited 2020 Nov 23]. Available from: https://pubmed.ncbi.nlm.nih.gov/31558366/.

34. Chhetri JK, de Souto Barreto P, Cantet C, Pothier K, Cesari M, Andrieu S, et al. Effects of a 3-year multi-domain intervention with or without omega-3 supplementation on cognitive functions in older subjects with increased CAIDE dementia scores. J Alzheimers Dis. 2018;64:71-8. https://doi.org/1 0.3233/JAD-180209.

35. van Middelaar T, Hoevenaar-Blom MP, van Gool WA, Moll van Charante EP, van Dalen JW, Deckers K, et al. Modifiable dementia risk score to study heterogeneity in treatment effect of a dementia prevention trial: a post hoc analysis in the preDIVA trial using the LIBRA index. Alzheimers Res Ther. 2018;10:62-4. https://doi.org/10.1186/s13195-018-0389-4.

36. Schiepers OJG, Kohler S, Deckers K, Irving K, O'Donnell CA, van den Akker M, et al. Lifestyle for Brain Health (LIBRA): a new model for dementia prevention. Int J Geriatr Psychiatry. 2018;33:167-75. https://doi.org/10.1002/ gps.4700.

37. Dubois $B$, Hampel H, Feldman HH, Scheltens P, Aisen P, Andrieu S, Bakardjian H, Benali H, Bertram L, Blennow K, Broich K, Cavedo E, Crutch S, Dartigues JF, Duyckaerts C, Epelbaum S, Frisoni GB, Gauthier S, Genthon R, Gouw AA, Habert MO, Holtzman DM, Kivipelto M, Lista S, Molinuevo JL, O'Bryant SE, Rabinovici GD, Rowe C, Salloway S, Schneider LS, Sperling R, Teichmann M, Carrillo MC, Cummings J, Jack CR Jr; Proceedings of the Meeting of the International Working Group (IWG) and the American Alzheimer's Association on "The Preclinical State of AD"; July 23, 2015; Washington DC, USA. Preclinical Alzheimer's disease: Definition, natural history, and diagnostic criteria. Alzheimers Dement. 2016;12(3):292-323. https://doi.org/10.1016/j.jalz.2016.02.002.

38. Dubois B, Feldman HH, Jacova C, Hampel H, Molinuevo JL, Blennow K, DeKosky ST, Gauthier S, Selkoe D, Bateman R, Cappa S, Crutch S, Engelborghs S, Frisoni GB, Fox NC, Galasko D, Habert MO, Jicha GA, Nordberg A, Pasquier F, Rabinovici G, Robert P, Rowe C, Salloway S, Sarazin M, Epelbaum S, de Souza LC, Vellas B, Visser PJ, Schneider L, Stern Y, Scheltens $P$, Cummings JL. Advancing research diagnostic criteria for Alzheimer's disease: the IWG-2 criteria. Lancet Neurol. 2014;13(6):614-29. https://doi.org/10.1016/S1474-4422(14)70090-0. Erratum in: Lancet Neurol. 2014;13(8):757.

39. O'Donnell CA, Browne S, Pierce M, McConnachie A, Deckers K, van Boxtel $M P$, et al. Reducing dementia risk by targeting modifiable risk factors in mid-life: study protocol for the Innovative Midlife Intervention for Dementia Deterrence (In-MINDD) randomised controlled feasibility trial. Pilot feasibility Stud. 2015;1:40. https://doi.org/10.1186/s40814--015-0035-x. eCollection2015.

40. Solomon A, Levälahti E, Antikainen R, Laatikainen T, Soininen H, Strandberg $\mathrm{T}$, et al. Effects of a multidomain lifestyle intervention on overall risk for dementia: the FINGER randomized controlled trial. Alzheimer's Dement. 2018;14:P1024-5. Elsevier; Available from:. https://doi.org/10.1016/j.jalz.2018. 06.2798.

41. Barbera M, Ngandu T, Lehvälahti E, Coley N, Mangialasche F, HoevenaarBlom $\mathrm{M}$, et al. Effect of multidomain interventions on estimated dementia and cardiovascular risk reduction: an individual-participant data metaanalysis from FINGER, MAPT, and Pre-DIVA. Alzheimer's Dement J Alzheimer's Assoc. 2020;16(S10). https://doi.org/10.1002/alz.039287. 
42. Coley N, Hoevenaar-Blom MP, van Dalen JW, Moll van Charante EP, Kivipelto $\mathrm{M}$, Soininen $\mathrm{H}$, et al. Dementia risk scores as surrogate outcomes for lifestyle-based multidomain prevention trials—rationale, preliminary evidence and challenges. Alzheimer's Dement. 2020; Wiley; [cited 2020 Sep 29]; Available from: https://pubmed.ncbi.nlm.nih.gov/32803862/.

43. Vuorinen M, Spulber G, Damangir S, Niskanen E, Ngandu T, Soininen $H_{\text {, }}$ et al. Midlife CAIDE Dementia Risk Score and dementia-related brain changes up to 30 years later on magnetic resonance imaging. J Alzheimer's Dis. 2015:44:93-101 IOS Press.

44. Enache D, Solomon A, Cavallin L, Kåreholt I, Kramberger MG, Aarsland D, et al. CAIDE Dementia Risk Score and biomarkers of neurodegeneration in memory clinic patients without dementia. Neurobiol Aging. 2016;42:124-31 Elsevier Inc.

45. Stephen R, Liu Y, Ngandu T, Rinne JO, Kemppainen N, Parkkola R, et al. Associations of CAIDE Dementia Risk Score with MRI, PIB-PET measures, and cognition. J Alzheimer's Dis. 2017;59:695-705 IOS Press.

46. Hooshmand B, Polvikoski T, Kivipelto M, Tanskanen M, Myllykangas L, Mäkelä M, et al. CAIDE Dementia Risk Score, Alzheimer and cerebrovascular pathology: a population-based autopsy study. J Intern Med. 2018;283:597603 Wiley (10.1111).

47. O'Brien JT, Firbank MJ, Ritchie K, Wells K, Williams GB, Ritchie CW, Su L Association between midlife dementia risk factors and longitudinal brain atrophy: the PREVENT-Dementia study. J Neurol Neurosurg Psychiatry. 2020; 91(2):158-61. https://doi.org/10.1136/jnnp-2019-321652. Epub 2019 Dec 5.

48. Cherbuin N, Shaw ME, Walsh E, Sachdev P, Anstey KJ. Validated Alzheimer's Disease Risk Index (ANU-ADRI) is associated with smaller volumes in the default mode network in the early 60s. Brain Imaging Behav. 2019;13:65-74 Springer New York LLC.

49. Johnson KA, Minoshima S, Bohnen NI, Donohoe KJ, Foster NL, Herscovitch P, et al. Appropriate use criteria for amyloid PET: a report of the Amyloid Imaging Task Force, the Society of Nuclear Medicine and Molecular Imaging, and the Alzheimer's Association. Alzheimers Dement. 2013;9 Available from: https:/ pubmed.ncbi.nlm.nih.gov/23360977/. [cited 2020 Dec 9].

50. Kaffashian S, Dugravot A, Elbaz A, Shipley MJ, Sabia S, Kivimäki M, et al. Predicting cognitive decline: a dementia risk score vs the Framingham vascular risk scores. Neurology. 2013;80(14):1300-6. https://doi.org/10.1212/ WNL.0b013e31828ab370.

51. Li SS, Zheng J, Mei B, Wang HY, Zheng M, Zheng K. Correlation study of Framingham risk score and vascular dementia: An observational study. Medicine (Baltimore). 2017;96(50):e8387. https://doi.org/10.1097/MD. 0000000000008387

52. Viticchi G, Falsetti L, Buratti L, Boria C, Luzzi S, Bartolini M, et al. Framingham risk score can predict cognitive decline progression in Alzheimer's disease. Neurobiol Aging. 2015;36:2940-5 Elsevier Inc.; [cited 2020 Nov 23]. Available from: https://pubmed.ncbi.nlm.nih.gov/26279114/.

53. Gourley D, Pasha EP, Kaur SS, Haley AP, Tanaka H. Association of Dementia and Vascular Risk Scores With Cortical Thickness and Cognition in Low-risk Middle-aged Adults. Alzheimer Dis Assoc Disord. 2020;34(4):313-7. https:// doi.org/10.1097/WAD.0000000000000392.

54. Torres S, Alexander A, O'Bryant S, Medina LD. Cognition and the predictive utility of three risk scores in an ethnically diverse sample. J Alzheimer's Dis. 2020;75:1049-59 IOS Press BV; [cited 2020 Nov 23]. Available from: https:// pubmed.ncbi.nlm.nih.gov/32390625/.

55. Lloyd-Jones DM, Hong Y, Labarthe D, Mozaffarian D, Appel LJ, Van Horn L, et al. Defining and setting national goals for cardiovascular health promotion and disease reduction: the American Heart Association's strategic impact goal through 2020 and beyond. Circulation. 2010:586-613 [cited 2020 Nov 23]. Available from: https://pubmed.ncbi.nlm.nih.gov/20089546/.

56. Sabia S, Fayosse A, Dumurgier J, Schnitzler A, Empana J-P, Ebmeier KP, et al. Association of ideal cardiovascular health at age 50 with incidence of dementia: 25 year follow-up of Whitehall II cohort study. BMJ. 2019;366: 14414 Available from: http://www.bmj.com/content/366/bmj.|4414.abstract.

57. Zeki Al Hazzouri A, Haan MN, Neuhaus JM, Pletcher M, Peralta CA, López L, et al. Cardiovascular risk score, cognitive decline, and dementia in older Mexican Americans: the role of sex and education. J Am Heart Assoc. 2013;2 [cited 2020 Nov 23]. Available from: https://pubmed.ncbi.nlm.nih.gov/23 $608609 /$.

58. Rundek T, Gardener H, Dias Saporta AS, Loewenstein DA, Duara R, Wright $\mathrm{CB}$, et al. Global vascular risk score and CAIDE Dementia Risk Score predict cognitive function in the Northern Manhattan Study. J Alzheimers Dis. 2020;
73:1221-31 NLM (Medline). [cited 2020 Nov 23]. Available from: https:// pubmed.ncbi.n/m.nih.gov/31884476/.

59. Tarraf W, Kaplan R, Daviglus M, Gallo LC, Schneiderman N, Penedo FJ, et al. Cardiovascular risk and cognitive function in middle-aged and older Hispanics/Latinos: results from the Hispanic Community Health Study/Study of Latinos (HCHS/SOL). J Alzheimer's Dis. 2020;73:103-16 IOS Press; [cited 2020 Nov 23]. Available from: https://pubmed.ncbi.nlm.nih.gov/31771064/.

60. Stephen $\mathrm{R}$, Soininen $\mathrm{H}$. Biomarker validation of a dementia risk prediction score. Nat Rev Neurol. 2020;16(3):135-6. https://doi.org/10.1038/s41582-0200316-8.

61. Duron $\mathrm{E}$, Hanon O. Vascular risk factors, cognitive decline, and dementia. Vasc Health Risk Manag. 2008;4(2):363-81. https://doi.org/10.2147/vhrm.s1839.

62. Kivipelto M, Mangialasche F, Snyder HM, Allegri R, Andrieu S, Arai H, et al. World-Wide FINGERS Network: a global approach to risk reduction and prevention of dementia. Alzheimer's Dement. 2020;16:1078-94 Wiley. [cited 2020 Sep 29]. Available from: https://pubmed.ncbi.nlm.nih.gov/32627328/.

63. Collins GS, Reitsma JB, Altman DG, Moons KGM. Transparent reporting of a multivariable prediction model for individual prognosis or diagnosis (TRIPOD): the TRIPOD statement. Ann Intern Med. 2015;162:55-63 Available from: https://pubmed.ncbi.nlm.nih.gov/25560714/. American College of Physicians; [cited 2020 Nov 23].

64. Alzheimer's Disease International. World Alzheimer Report 2019: Attitudes to dementia. London: Alzheimer's Disease International; 2019.

65. Beishuizen CRL, Coley N, van Charante EP, van Gool WA, Richard E, Andrieu S. Determinants of dropout and nonadherence in a dementia prevention randomized controlled trial: the Prevention of Dementia by Intensive Vascular Care Trial. J Am Geriatr Soc. 2017;65:1505-13 Available from: https://doi.org/10.1111/jgs.14834.

66. Coley N, Ngandu T, Lehtisalo J, Soininen H, Vellas B, Richard E, et al. Adherence to multidomain interventions for dementia prevention: data from the FINGER and MAPT trials. Alzheimer's Dement. 2019;15:729-41 Wiley. Available from: https://doi.org/10.1016/j.jalz.2019.03.005.

67. Rosenberg A, Coley N, Soulier A, Kulmala J, Soininen H, Andrieu S, et al. Experiences of dementia and attitude towards prevention: a qualitative study among older adults participating in a prevention trial. BMC Geriatr. 2020;20:99 BioMed Central Ltd. [cited 2020 Nov 23]. Available from: https:// bmcgeriatr.biomedcentral.com/articles/10.1186/s12877-020-1493-4.

\section{Publisher's Note}

Springer Nature remains neutral with regard to jurisdictional claims in published maps and institutional affiliations. 